\title{
Passenger Car Equivalents for Vehicles at Signalized Intersections within the Kumasi Metropolis in Ghana
}

\author{
*A. A. Obiri-Yeboah, Y. A. Tuffour, M. Salifu \\ ${ }^{l}$ Civil Engineering Department, Kumasi Polytechnic, P. O. Box 854 Kumasi, Ghana \\ ${ }^{2}$ Civil Engineering Department, Kwame Nkrumah University of Science and Technology, \\ Kumasi, Ghana
}

\begin{abstract}
Passenger car equivalents (PCEs) used in Ghana have been adopted from other countries and, therefore, cannot be said to capture the impact of local conditions in signalized intersection analysis. In this study, passenger car equivalents were evaluated for three vehicle categories; cars, medium vehicles, and trucks, which use signalized intersections within the Kumasi Metropolis, Ghana. The objective was to develop PCEs which truly reflect the prevailing traffic mix, flow conditions and the effect of roadside friction at the intersections. Data was collected on discharge headways at eleven signalized intersections controlled by pretimed signals,and using the headway ratio method, PCEs of the three categories of vehicles were estimated. PCE values were higher at intersections with roadside friction than those at intersections devoid of such friction. In comparison, the values obtained from the study are larger than those adopted from elsewhere and probably reflect more accurately the impact of local conditions on discharge at the intersections. This underscores the need to develop PCEs appropriate to local conditions rather than adopt from other standards.
\end{abstract}

Keywords:-Headway, Passenger Car Equivalent, Saturation Flow Rate, Signalized Intersections

\section{INTRODUCTION}

Different categories of vehicles, by virtue of their different space requirements and performance attributes, influence the discharge headways of vehicles at signalized intersections differently. A traffic stream composed of a high presence of heavy and slow-moving vehicles is most likely to be associated with discharge headways larger than those of a stream composed of predominantly small and fast-moving vehicles. Vehicle length, performance, and driver behavior have been identified as the major factors which influence headways [1]. However, in many developing country cities and metropolitan areas, the nature of roadside land use and activities in the immediate vicinity of intersections could have an impact on the quality of traffic flow at such locations. To account for the effects of each vehicle type on the quality of flow, a traffic stream composed of a mix of vehicle types is converted to an equivalent stream composed entirely of passenger cars using passenger car equivalent (PCE) values [2,3].

The term "passenger car equivalent" as originally introduced and defined in the 1965 Highway Capacity Manual (HCM) is "the number of passenger cars displaced in the traffic flow by a truck or a bus, under the prevailing roadway and traffic conditions". Today, the definition remains essentially the same in HCM 2010as "the number of passenger cars that will result in the same operational conditions as a single heavy vehicle of a particular type under specified roadway, traffic, and control conditions" [4]. Simply put, the passenger car equivalent of a vehicle represents the number of passenger cars that would have an equivalent effect on the quality of the traffic flow under prevailing conditions [5]. In some countries, the heterogeneous nature of local traffic has led to the expansion of the scope of PCEs to include even non-motorized vehiclessuch as rickshaws, bullock carts, and handcarts [6].

The need to convert heterogeneous traffic to one composed entirely of passenger cars arises during the design of signalized intersections and estimation of the capacity of existing ones when saturation flow rates are required as input parameter. In signal design, without such conversion, approach streams with substantial presence of heavy and other slow-moving vehicles would be disadvantaged in the allocation of green times. In another context, Sumner et al. [7] have suggested a possible use of PCEs in highway cost allocation to individual vehicle types using urban arterial roads according to their vehicle hour of usage.

In the analysis of signalized intersections, the use of measured saturation flow rates is often recommended and this requires collection of data from the field.Since the introduction of the concept of PCEs, efforts have been directed at developing relationships for the estimation of the parameter, but according to [2], at present, a commonly-accepted and clearly-defined theoretical basis for the concept is yet to be found. Nevertheless, almost all PCE evaluation techniques tend to be based on one type of traffic flow variable or another. While most PCE estimation approaches use headways[1,8-10], others are based on speeds [11], delay 
[12-14], density [5,15], travel time [16] and even platoon formation [11]. Whichever approach is used, the outcome shouldreflect prevailing local conditions and the character of local traffic.

In Ghana, transportation engineers and professionals rely on PCEs adopted from the Overseas Road Note 11 [17]for signalized intersection analysis without local validation. But in many urban/metropolitan areas in the country, road side economic activities and vehicular and pedestrian activities at public transport stops, taxi ranks and sometimes fuel stations,located in close proximity to signalized intersections,tend to interfere with discharge through such intersections. The impact of such roadside friction is lost if intersection analysis is carried out using PCEs adopted from other countries with dissimilar traffic flow and road environmental conditions. This study was meant to develop PCEs appropriate for intersection analysis within the Kumasi Metropolis in Ghana.

\section{STUDY SITES}

Site selection was based on the recommendation [18] that signalized intersections being studied should be fully saturated or have adequately saturated portions of the green interval of longer than 20 seconds with cycle lengths greater than 30s. In all, a total of 11 signalized intersections, all controlled by pre-timed signals were selected within the Kumasi Metropolis (see Fig.1).

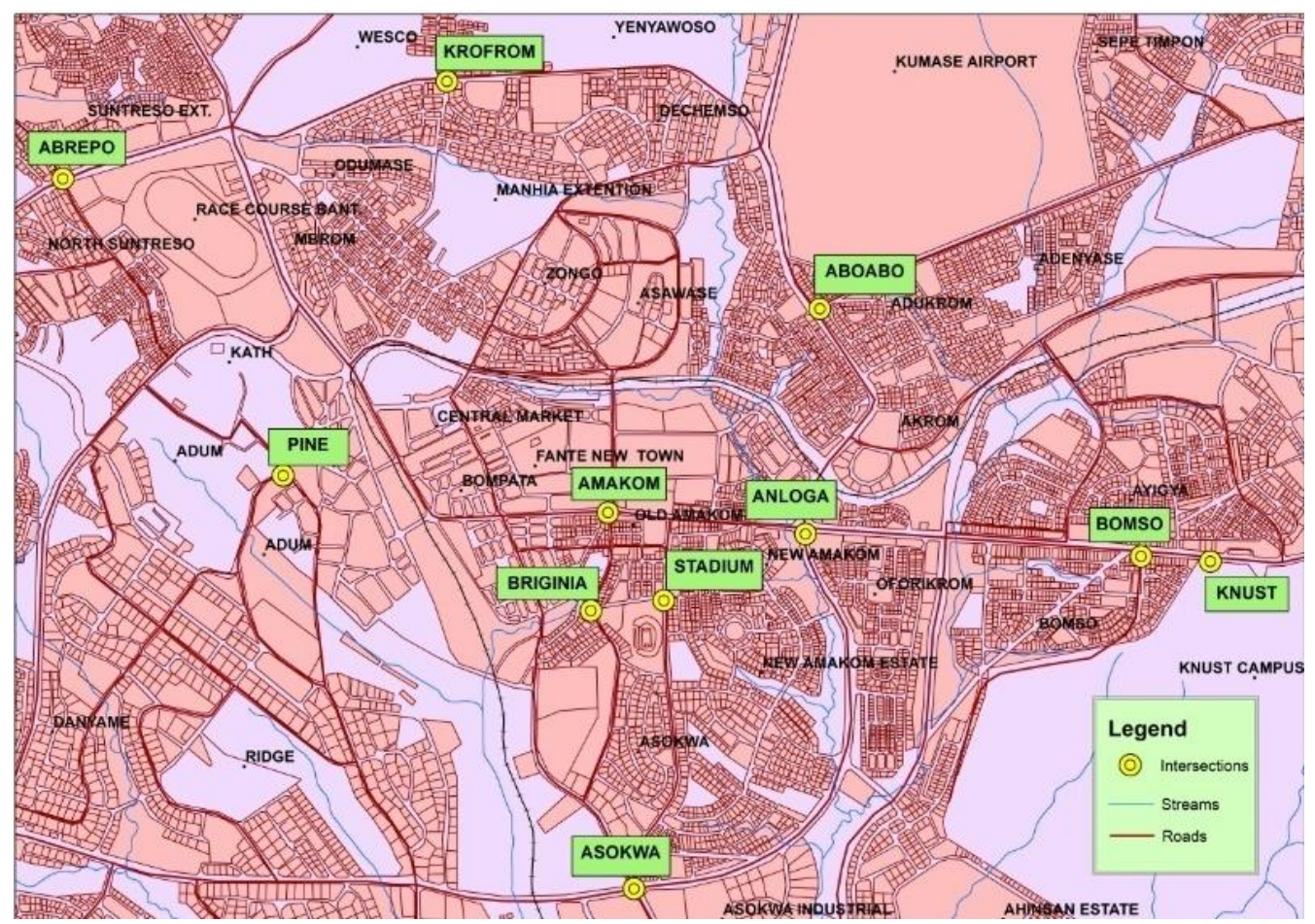

Figure 1. Map of Kumasi showing locations of selected intersections

Within close proximity to seven of the intersections were at least one of the following facilities; bus stop, taxi rank, and fuel station, whose activities tended to interfere with the discharge of vehicles at the intersections. The remaining four intersections were devoid of the presence of any such facilities. Table 1 provides a summary description of the intersections and their approaches, the number of approach lanes available and the presence or otherwise of either a bus stop, or taxi rank or fuel station or a combination, within close proximity to the locations.

Table 1. Site characteristics of selected intersections

\begin{tabular}{|c|c|c|c|}
\hline Intersection Name & Approach & $\begin{array}{c}\text { Number of } \\
\text { Lanes }\end{array}$ & $\begin{array}{c}\text { Bus stop/Taxi } \\
\text { Rank/Fuel Station }\end{array}$ \\
\hline \multirow{2}{*}{ Bomso } & University & 2 & Present \\
\cline { 2 - 4 } & Top High & 2 & Present \\
\hline \multirow{2}{*}{ Anloga } & Oforikrom & 2 & Present \\
\cline { 2 - 4 } & Afful Nkwanta & 2 & Present \\
\hline \multirow{2}{*}{ Amakom } & Afful Nkwanta & 2 & Present \\
\cline { 2 - 4 } & Labour & 2 & Present \\
\hline
\end{tabular}


Table 2 continued

\begin{tabular}{|c|c|c|c|}
\hline Intersection Name & Approach & $\begin{array}{c}\text { Number of } \\
\text { Lanes }\end{array}$ & $\begin{array}{c}\text { Bus stop/Taxi } \\
\text { Rank/Fuel Station }\end{array}$ \\
\hline \multirow{2}{*}{ Pine Avenue } & Adum & 1 & Absent \\
\cline { 2 - 4 } & Officers Mess & 1 & Absent \\
\hline \multirow{2}{*}{ Asokwa } & Asafo & 2 & Absent \\
\cline { 2 - 4 } & Atonsu & 2 & Absent \\
\hline \multirow{2}{*}{ Krofrom } & Dichemso & 2 & Present \\
\cline { 2 - 4 } & Suame & 2 & Present \\
\hline \multirow{2}{*}{ Aboabo } & Anloga & 2 & Present \\
\cline { 2 - 4 } & Dichemso & 2 & Present \\
\hline \multirow{2}{*}{ Kriginia Spot } & Top High & 2 & Present \\
\cline { 2 - 4 } & Kentikrono & 2 & Absent \\
\cline { 2 - 4 } & Stadium & 1 & Absent \\
\hline \multirow{2}{*}{ Stadium } & Asafo & 1 & Absent \\
\cline { 2 - 4 } & Children's Park & 1 & Absent \\
\hline \multirow{2}{*}{ Abrepo Junction } & Asokwa & 1 & Present \\
\cline { 2 - 4 } & Suame & 2 & Present \\
\hline
\end{tabular}

\section{DATA COLLECTION AND PROCESSING}

Traffic flow for through lane movements was recorded from the 22 approachesdetailed in Table 1. A portable digital camcorder with tripod was used to record real time traffic movements as the vehicles discharged through the intersection during the green interval. Data was collected during the morning peak period only from 7am-9am in March and November, 2013 and January, 2014. Headways were then extracted from the video recordings using the playback method on a computer screen. The headway data was sorted out for three categories of vehicles; cars (C) (small cars, pickups, and taxis), medium vehicles (M) (small and medium buses) and trucks (T) (large buses, light, medium and heavy trucks and trailers). Estimation of the PCE valuefor a given vehicle category $i$ wasbased on the headway ratio method given by the expression:

$$
P C E_{i}=H_{i} / H_{B}
$$

Where, $P C E_{i}$ is the passenger car equivalent of vehicle category $i, H_{i}$ is the average headway of vehicle category $i$ under prevailing conditions, and $H_{B}$ is the average headway of passenger cars under the same conditions.

\section{IV.}

\section{RESULTS AND DISCUSSION}

Table 2 contains the headway data extracted from the video recordings and sorted out for the three categories of vehicles and intersections with and without roadside friction. The contents of the table show grouping of intersections which is only an indication of common periods of field data collection. For a given vehicle category, the data showsaverage headways at the intersections without side friction to traffic flow being generally lower than those at intersections where there is some side friction. Frictionin such flow environments tended tomanifestin the form of slowdown of discharging vehicles as downstream vehicles diverge to the facilities and othersfrom the facilities attempt to merge with the through traffic. These actions imposed larger headways on the discharging vehicles, particularly large vehicles as such vehicleswhen slowed down are known totakerelatively longer time to accelerate to re-establish their speeds ante.

PCE values evaluated from the average headways have been detailed in Table 3 for intersections affected by roadside friction and those devoid of such friction. It is seen from the table that the PCE values were higher where there was side friction. The impactof side frictionappeared to be particularly more severe on the heavy vehicles than the other categories of vehicles.

Table 2. Headways (in seconds) extracted from video recordings at study sites

\begin{tabular}{|c|c|c|c|c|c|c|c|c|c|c|c|c|}
\hline \multirow{3}{*}{$\begin{array}{l}\text { Ser. } \\
\text { No. }\end{array}$} & \multicolumn{6}{|c|}{ Intersections with Roadside Friction } & \multicolumn{6}{|c|}{ Intersections without Roadside Friction } \\
\hline & \multicolumn{3}{|c|}{ KNUST/Bomso/Anloga/Amakom } & \multicolumn{3}{|c|}{$\begin{array}{c}\text { Abrepo/Krofrom/ } \\
\text { Aboabo }\end{array}$} & \multicolumn{3}{|c|}{$\begin{array}{c}\text { Asokwa/Briginia/ } \\
\text { Stadium }\end{array}$} & \multicolumn{3}{|c|}{ Pine Avenue } \\
\hline & $\mathbf{C}$ & $\mathbf{M}$ & $\mathbf{T}$ & $\mathbf{C}$ & $\mathbf{M}$ & $\mathbf{T}$ & $\mathbf{C}$ & $\mathbf{M}$ & $\mathbf{T}$ & $\mathbf{C}$ & $\mathbf{M}$ & $\mathbf{T}$ \\
\hline 1 & 1.62 & 3.33 & 5.04 & 1.57 & 3.56 & 5.13 & 1.89 & 3.12 & 4.76 & 2.57 & 3.15 & 5.76 \\
\hline 2 & 1.83 & 2.34 & 4.45 & 1.79 & 2.34 & 4.54 & 1.88 & 2.48 & 4.15 & 2.88 & 2.57 & 5.04 \\
\hline
\end{tabular}


Passenger Car Equivalents for Vehicles at Signalized Intersections within the Kumasi...

Table 2 continued

\begin{tabular}{|c|c|c|c|c|c|c|c|c|c|c|c|c|}
\hline \multirow{3}{*}{$\begin{array}{l}\text { Ser. } \\
\text { No. }\end{array}$} & \multicolumn{6}{|c|}{ Intersections with Roadside Friction } & \multicolumn{6}{|c|}{ Intersections without Roadside Friction } \\
\hline & \multicolumn{3}{|c|}{ KNUST/Bomso/Anloga/Amakom } & \multicolumn{3}{|c|}{$\begin{array}{c}\text { Abrepo/Krofrom/ } \\
\text { Aboabo }\end{array}$} & \multicolumn{3}{|c|}{$\begin{array}{c}\text { Asokwa/Briginia/ } \\
\text { Stadium }\end{array}$} & \multicolumn{3}{|c|}{ Pine Avenue } \\
\hline & C & $\mathbf{M}$ & $\mathbf{T}$ & $\mathbf{C}$ & $\mathbf{M}$ & $\mathbf{T}$ & $\mathbf{C}$ & $\mathbf{M}$ & $\mathbf{T}$ & $\mathbf{C}$ & $\mathbf{M}$ & $\mathbf{T}$ \\
\hline 3 & 1.78 & 2.11 & 3.37 & 1.78 & 2.23 & 3.73 & 1.98 & 2.97 & 3.84 & 1.98 & 2.79 & 4.84 \\
\hline 4 & 1.48 & 2.86 & 3.58 & 1.96 & 2.86 & 3.58 & 2.56 & 2.51 & 5.32 & 2.52 & 3.51 & 5.23 \\
\hline 5 & 1.27 & 2.81 & 4.00 & 1.37 & 2.81 & 4.21 & 2.57 & 3.64 & 3.98 & 2.75 & 3.87 & 3.78 \\
\hline 6 & 1.84 & 2.57 & 2.44 & 1.84 & 2.57 & 2.54 & 2.34 & 4.19 & 4.15 & 2.43 & 4.05 & 5.15 \\
\hline 7 & 1.53 & 2.33 & 5.63 & 1.56 & 2.86 & 5.36 & 2.25 & 4.33 & 4.67 & 2.52 & 3.33 & 4.87 \\
\hline 8 & 1.61 & 2.41 & 2.96 & 1.59 & 3.14 & 3.96 & 2.29 & 2.43 & 4.85 & 2.31 & 2.43 & 4.68 \\
\hline 9 & 1.82 & 2.34 & 4.56 & 1.89 & 2.34 & 4.56 & 2.04 & 2.87 & 6.24 & 2.03 & 2.66 & 6.12 \\
\hline 10 & 1.31 & 2.74 & 7.77 & 1.36 & 2.74 & 6.79 & 1.99 & 3.42 & 5.24 & 1.98 & 3.24 & 4.26 \\
\hline 11 & 1.36 & 2.42 & 8.05 & 1.36 & 2.34 & 8.15 & 2.32 & 3.61 & 4.76 & 2.31 & 3.42 & 3.78 \\
\hline 12 & 1.35 & 2.72 & 7.51 & 1.35 & 2.72 & 5.15 & 2.16 & 2.19 & 5.43 & 3.26 & 2.84 & 5.34 \\
\hline 13 & 1.47 & 2.26 & 6.21 & 1.74 & 2.97 & 6.35 & 2.06 & 2.56 & 5.24 & 2.16 & 3.56 & 5.15 \\
\hline 14 & 1.14 & 2.66 & 2.59 & 1.26 & 2.66 & 5.59 & 2.48 & 2.23 & 3.97 & 2.84 & 2.98 & 3.91 \\
\hline 15 & 1.72 & 2.13 & 2.85 & 1.72 & 2.53 & 4.85 & 2.12 & 2.46 & 5.46 & 2.21 & 3.86 & 4.56 \\
\hline 16 & 1.72 & 2.18 & 4.61 & 1.59 & 2.48 & 4.16 & 3.49 & 3.41 & 3.79 & 1.94 & 4.13 & 4.79 \\
\hline 17 & 1.78 & 2.43 & 6.92 & 1.78 & 2.43 & 5.29 & 2.16 & 2.49 & 3.42 & 1.62 & 2.68 & 3.59 \\
\hline 18 & 1.48 & 2.17 & 7.41 & 1.96 & 2.87 & 6.14 & 2.18 & 2.56 & 4.93 & 2.07 & 3.52 & 5.93 \\
\hline 19 & 1.18 & 2.08 & 5.48 & 1.67 & 2.68 & 4.56 & 2.25 & 2.26 & 5.81 & 2.52 & 3.26 & 6.18 \\
\hline 20 & 1.74 & 2.57 & 6.36 & 1.74 & 2.57 & 6.36 & 1.98 & 2.21 & 4.12 & 1.84 & 3.98 & 4.21 \\
\hline 21 & 1.69 & 2.79 & 4.45 & 1.69 & 2.79 & 5.16 & 2.43 & 2.94 & 3.68 & 2.34 & 3.46 & 3.97 \\
\hline 22 & 1.27 & 2.44 & 3.72 & 1.87 & 2.44 & 4.57 & 2.12 & 2.21 & 5.18 & 2.12 & 3.21 & 5.17 \\
\hline 23 & 1.75 & 2.38 & 4.58 & 1.75 & 2.31 & 4.58 & 2.16 & 3.16 & 4.56 & 1.44 & 3.16 & $\overline{6.15}$ \\
\hline 24 & 1.56 & 2.95 & 2.62 & 1.36 & 2.95 & 2.29 & 2.31 & 2.86 & 5.38 & 2.57 & 2.68 & 6.38 \\
\hline 25 & 1.44 & 4.16 & 2.51 & 1.56 & 4.16 & 3.15 & 1.49 & 2.59 & 5.97 & 1.76 & 2.59 & 5.97 \\
\hline 26 & 1.29 & 2.47 & 5.29 & 1.76 & 2.47 & 5.29 & 1.13 & 2.64 & 5.14 & 1.31 & 2.57 & 5.79 \\
\hline 27 & 1.21 & 3.11 & 2.93 & 1.89 & 2.11 & 3.92 & 1.62 & 3.28 & 5.79 & 1.81 & 3.01 & 5.14 \\
\hline 28 & 1.31 & 2.33 & 5.38 & 1.63 & 2.33 & 5.18 & 2.08 & 2.97 & 5.34 & 2.12 & 2.97 & 5.19 \\
\hline 29 & 1.43 & 2.64 & 4.84 & 1.43 & 2.97 & 5.74 & 2.06 & 3.71 & 4.98 & 2.21 & 3.17 & 4.98 \\
\hline 30 & 1.73 & 3.32 & 5.05 & 1.73 & 3.32 & 5.15 & 2.34 & 2.69 & 5.16 & 2.34 & 2.96 & 5.11 \\
\hline AVG. & 1.52 & 2.6 & 4.77 & 1.65 & 2.72 & 4.87 & 2.16 & 2.9 & 4.84 & 2.23 & 3.19 & 5.03 \\
\hline
\end{tabular}

Table 3. PCE values evaluated from study

\begin{tabular}{|c|c|c|}
\hline \multirow{2}{*}{ Vehicle Category } & \multicolumn{2}{|c|}{ Intersection Type } \\
\cline { 2 - 3 } & $\begin{array}{c}\text { With Roadside } \\
\text { Friction }\end{array}$ & $\begin{array}{c}\text { Without Roadside } \\
\text { Friction }\end{array}$ \\
\hline Cars (C) & 1.00 & 1.00 \\
\hline Medium Vehicles (M) & 1.65 & 1.35 \\
\hline Trucks (T) & 3.05 & 2.25 \\
\hline
\end{tabular}


PCE values adopted from the Overseas Road Note 11 [17] are 1.00, 1.10, and 2.25 for cars, medium vehicles and trucks, respectively. In comparison, the values obtained from this study are larger and probably reflect more accurately the impact of local conditions on discharge through the signalized intersections. This underscores the need to develop PCEs appropriate to local conditions rather than adopt from foreign standards.

\section{CONCLUSION}

This paper presented estimation of PCEsfor the traffic mix and flow conditions prevailing at signalized intersections within the Kumasi Metropolis, Ghana. The estimation procedure used the headway method. Vehicles considered were placed in three categories; cars, medium vehicles and trucks. The PCEs developed from this study were 1.0, 1.65, and 3.05 for cars, medium vehicles and trucks, respectively,at intersections where roadside friction to flow existed. Where such friction did not exist, the values were 1.0, 1.35, and 2.25 for cars, medium vehicles, and trucks, respectively, which were much lower. The differences in PCE values for corresponding categories of vehicles in the two situations are believed to be a reflection of the impact of roadside friction to vehicular flow at the intersections, which appeared to be more severe on trucks than the other vehicle categories. PCE values which have been adopted from the Overseas Road Note 11 [17] are 1.00, 1.10, and 2.25 for cars, medium vehicles and trucks, respectively, which in comparison to the values obtained in this study are lower. It is recommended that PCE values from this study be used in intersection analysis within the Kumasi Metropolis as they are believed to reflect better and more accurately the impact of local conditions on discharge at the intersections.

\section{REFERENCES}

[1] K.M. Kochelman, and R.A. Shabih, Effect of Light-Duty Trucks on the Capacity of Signalized Intersections, Journal of Transportation Engineering, Vol. 126, Issue 6, November, 2000, pp 506-512.

[2] M. Rahman, and F. Nakamura, Measuring passenger car equivalents for non-motorized vehicle (Rickshaws) at mid-block sections,Journal of the Eastern Asia Society for Transportation Studies, Vol. 6, 2005, pp 119-126.

[3] L. Vien, Ibrahim, W.H.W., and A.F. Mohd, Passenger Car Equivalents and Saturation Flow Rates for Through Vehicles at Signalized Intersections in Malaysia, $22^{\text {nd }}$ ARRB Conference -Research into Practice, 2006, Canberra, Australia.

[4] Highway Capacity Manual (HCM) 2010. TRB, National Research Council, Washington, DC.

[5] N. Webster, andL. Elefteriadou, A simulation study of truck passenger car equivalents (PCE) on basic freeway sections, Transportation Research Part B: Methodological, Vol. 33, Issue 5, June 1999, pp 323336.

[6] M. Metkari, A.K. Budhkar, and A.K. Maurya, Review of Passenger Car Equivalence Studies in Indian Context,International Conference on Emerging Frontiers in Technology for Rural Areas (EFITRA), 2012.

[7] R. Sumner, D. Hill, and S. Shapiro,Segment passenger car equivalent values for cost allocation on urban arterial roads,Transportation Research Part A: General, Vol. 18, Issues 5-6,October-December, 1984, pp 399-406.

[8] A. Werner, and J. Morrall, Passenger Car Equivalencies of Trucks, Buses, and Recreational Vehicles for Two-Lane Rural Highways,Transportation Research Record 615, pp10-17, 1976,TRB, National Research Council, Washington, D.C.

[9] R.Krammer, and K.Crowley, Passenger car Equivalents for Trucks on Level Freeway Segments,Transportation Research Record 1091,1986, pp 10-17,TRB, National Research Council, Washington, D.C.

[10] A. Anwaar, D.V. Boxel, M. Volovski, P.C. Anastasopoulos, and K.C. Sinha, Using Lagging Headways to Estimate Passenger Car Equivalents on Basic Freeway Sections,Journal of Transportation, ITE, Vol.1, Issue 2, 2011.

[11] M. Van Aerde, and S. Yagar, Capacity, Speed, and Platoon Vehicle Equivalents for Two-Lane Rural Highways,Transportation Research Record 971, 1984, pp 58-67, TRB, National Research Council, Washington, D.C.

[12] Elefteriadou, L., Torbic, D., and Webster, N.Development of Passenger Car Equivalents for Freeways, Two-Lane Highways, and Arterials, Transportation Research Record 1572, 1997, pp 51-58.

[13] J. Craus, A. Polus, and I. Grinberg, A revised method for the determination of passenger car equivalents,Transportation Research, Vol. 14A, No. 4, 1980, pp 241-246.

[14] R.F. Benekohal, and W. Zhao, Delay-based passenger car equivalents for trucks at signalized intersections, Transportation Research Part A: Policy and Practice, Vol. 34, Issue 6, August 2000, pp 437-457. 
[15] S.H. Demarchi, and J.R. Setti, Limitation of Passenger-Car Equivalent Derivation for Traffic Streams with more than One Truck Type, Transportation Research Record 1852, 2003, TRB, National Research Council, Washington, D.C.

[16] E.L. Keller, and J.G. Saklas, Passenger car equivalents from network simulation,Journal of Transportation Engineering, Vol. 110. No. 4, 1984, pp 397-411.

[17] Transport Research Laboratory,Urban Road Traffic SurveysOverseas Road Note 11, 1993, Crowthorne, Berkshire, United Kingdom.

[18] S. Teply, D.I. Allingham, D.B. Richardson,and B.W. Stephenson,Canadian Capacity Guide for Signalized Intersections, Third edition, 2008, District 7,Institute of Transportation Engineers, Canada. 